\title{
Facilitating Mine Closure with a Continuous Analysis and Review System
}

\author{
D.J. Tongway CSIRO Sustainable Ecosystems, Australia
}

\begin{abstract}
It is rare but not unknown for a sustained "cradle to grave" effort to be applied in restoring lands affected by mining. The author suggests that a logical sequence of data gathering and analysis be used to make sure that the most appropriate soil materials, landforms and vegetation are selected for use, and that trends in ecosystem functioning are well-recorded, so that personnel changes do not derail the closure process. The author proposes that a system of acquiring information relevant to achieving the ultimate objectives of the post-mining land be implemented from the earliest possible stage and that the knowledge so acquired be acted on throughout the mine life to keep rehabilitation on track, so that closure is as smooth a process as possible. The approach is intended to stop unthinking "recipe book" solutions; each mine would have its unique factors properly investigated.
\end{abstract}

\section{Introduction}

It is common knowledge that personnel changes and lack of consistent management support tends to militate against a smooth progression towards successful rehabilitation and mine closure. Mines where these factors have been maintained tend to be among the most successful in rehabilitation (Grant 2006, 2007; Spain et al., 2006). If planning for closure is an active, supported process from the earliest possible time, for example exploration, the identification of appropriate materials for new landforms and ecosystems and their careful maintenance during the mining phase would expedite achieving the ultimate rehabilitation goals. This implies that resources to identify threats and opportunities need to be made available, that analysis of the incoming data needs to be prompt and resulting in immediate, effective management action. The process is open to fostering and designing new research and incorporating the findings, when deemed necessary - an adaptive learning process.

\section{A logical sequence of information gathering, analysis and decision-making}

The author proposes that the model depicted in Figure 1 represents a sequence of information gathering, prompt analysis and decision-making that could be implemented from the very earliest stage in mine proposition.

This figure acknowledges that the legal and social drivers for mine site rehabilitation, the top left hand cloud, come from outside the industry and vary from place to place (Cobby, 2007; Sutton and Weiersbye, 2007).

There is limited scope to modify these requirements, but their intention needs to be well-understood. This is explained in the following steps and by the boxes in Figure 1. 


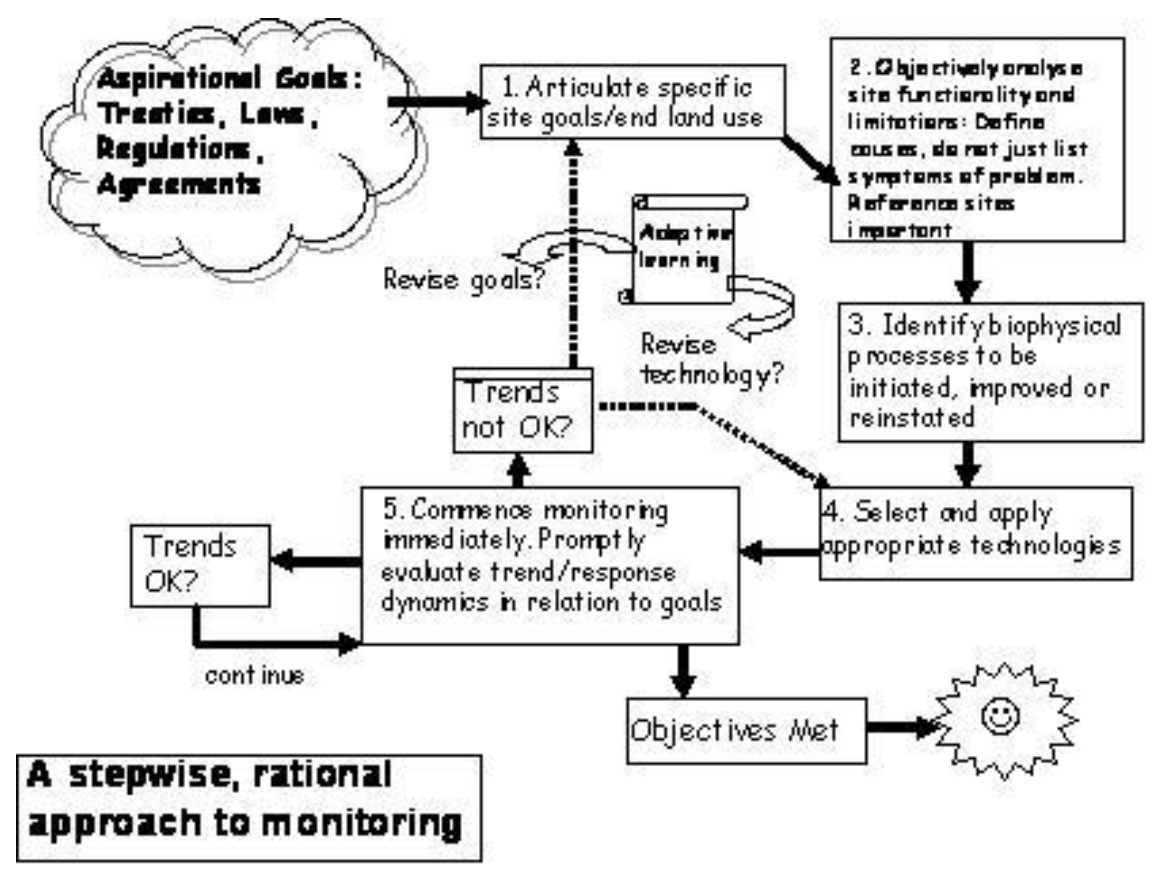

Figure 1 A conceptual framework depicting the sequence of problem solving, rehabilitation actions and monitoring

\subsection{Step 1}

In Box 1, all of the various stakeholder issues need to be resolved, tensions relieved and a shared objective hammered out. This is not a trivial task, and may involve compromises by several stakeholders. It is this agreed position that is the starting point for rehabilitation planning and action. It is crucial that this phase is committed to actions to reach the objectives, and that the stated objectives are measurable by accepted procedures, rather than just crafting a nice set of words.

\subsection{Step 2}

Box 2 provides for the first input to the rehabilitation process and involves analyzing the needs of the final landscape and its users, as specified in Box 1, an understanding of the possible landforms and the nature of the materials from which they would be built. Issues such as off-site contamination, erosion/deposition and biological system establishment need to be resolved. In many mines, soil materials with highly dispersive character are often excavated in the stripping process. This property needs to be evaluated promptly so that appropriate plans to re-bury this material, and not use it as a surface layer, can be made. On the other hand, surface soils with appropriate seed banks and other beneficial soil biota also need to be evaluated for their use as topsoils and then managed so that their physical and biological benefits are maximized (Spain et al., 2006). Land forms for waste rock dumps and tailings storage facilities (TSFs) should also be decided at this stage, with a strong input from landform evolution experts and biologists, to ensure that built landforms will maximize the opportunity for low net erosion over long time periods and facilitate rapid development of vegetation cover and successional processes. Weiersbye (pers. comm., 2008) has shown that with small but significant changes to "standard procedures", namely a reduction in slope to $16^{\circ}$, erosion was greatly reduced: close inspection confirmed very little soil movement between adjacent grass clumps in an upslope/downslope direction and the edaphic habitat for vegetation establishment enhanced at the same time. 


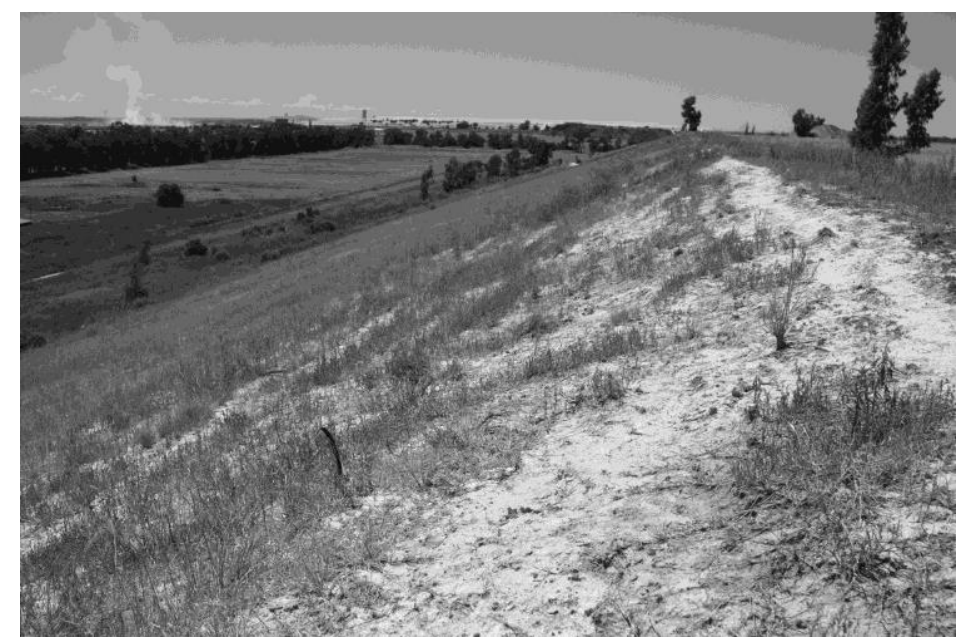

Figure 2 A TSF external wall adjusted to a $16^{\circ}$ slope, with an abundant grass cover still remaining 10 years after planting. Note also that runoff from the top surface over the external slope has not occurred

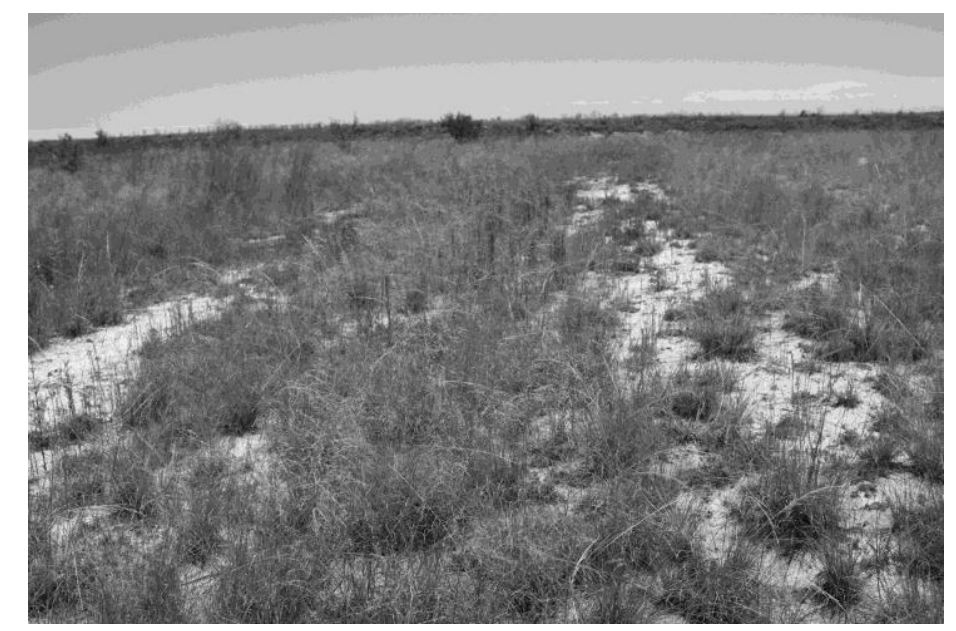

Figure 3 Top of a TSF micro-contoured to create run-off (bare) and adjacent run-on (grassy) zones

A run-off/run-on microtopography, comprised of rises and swales was also created at an appropriate scale on the top of the TSF (Figure 3) thus facilitating very high grass cover on the run-on zones. For the whole TSF surface, this comprises an appropriate store and release design, where the efficient storage of incident rain in the swales allows the high grass biomass to develop without irrigation. The grassy patches also prevent high volumes of water flowing off and over the TSF top at high velocity. Landform slope and footprint are decision areas where mining engineers traditionally dominate, but very often the resulting landforms and material use is counter-productive for ecosystem establishment and mine closure. This is a key area for harmonization of the different "cultures" in mine management.

\subsection{Application of principles}

The above are examples of "getting it right" at the design stage, having taken note of the long-term objectives and making appropriate use of the materials available. Typically, such designed landscapes can be monitored with the "landscape organization" step in landscape function analysis (LFA), which at early stages of ecosystem establishment, specifically examines water, sediment and micro land-form movement as affected initially by climate impacting engineered landform and surface materials (Tongway and Hindley, 2004). At later stages, the role of developing vegetation in delivering the service of regulating the outflow dynamics of mobile resources and the development of a nutrient cycle can also be assessed. It is at this stage that any soil property deficiencies need to be made good. For example, the creation of appropriate micro- 
topography, soil nutrient deficiencies or toxicity and species composition. Designing in high quality topsoil management to make use of soil biology is an important activity in this phase, delivering vital outcomes in terms of vascular plant species composition and soil biological processes (Grant, 2006; Spain et al., 2006). On TSFs, innovative techniques may be needed.

The level of landscape function understanding expected at this stage should develop to become "predictive" in terms of the evolving landscape processes. The author suggests that knowledge at this level enables early intervention in systems which are slightly off-track, by focusing on the appropriate basic processes, rather than waiting for the failure of some other indicator whose information comes only after a time delay.

\section{The value of reference sites}

Reference sites are extremely important for both the biophysical and social aspects of rehabilitation. The reference sites need to represent a credible model for the functioning of the rehabilitated land and to provide the wealth of diverse information needed to judge how well the rehabilitation is trending. Reference site selection criteria should be negotiated in the Box 1 discussions, having regard to what is socially and ecologically possible. In the case of unconfined slimes dams, old sites with satisfactory rehabilitation, for whatever reason, might be considered as appropriate, depending on the Box 1 negotiations. Data from reference sites over time will also reflect the "response to season" and also to rare disturbances such as fires and storms. Reference sites may provide information about slope angles and cover types that could be emulated in the rehabilitation, which is positive feedback to Box 2. LFA uses the term "analogue sites", meaning that the selected sites should indicate the manner in which vital resources are regulated, conserved and used, rather than necessarily having the same biotic complement, which would be described as "homologues". The underlying concept being that if the rehabilitating landscape is set up to regulate the use and flux of these resources in an analogous manner to the reference site, then a stable, predictable and increasingly complex ecosystem will develop. Once this stage is reached, more ultimate goals such as a specified species complement and the acquisition of a high degree of resilience in the face of rare stress and disturbance events can be contemplated and assessed with an evolving set of monitoring tools.

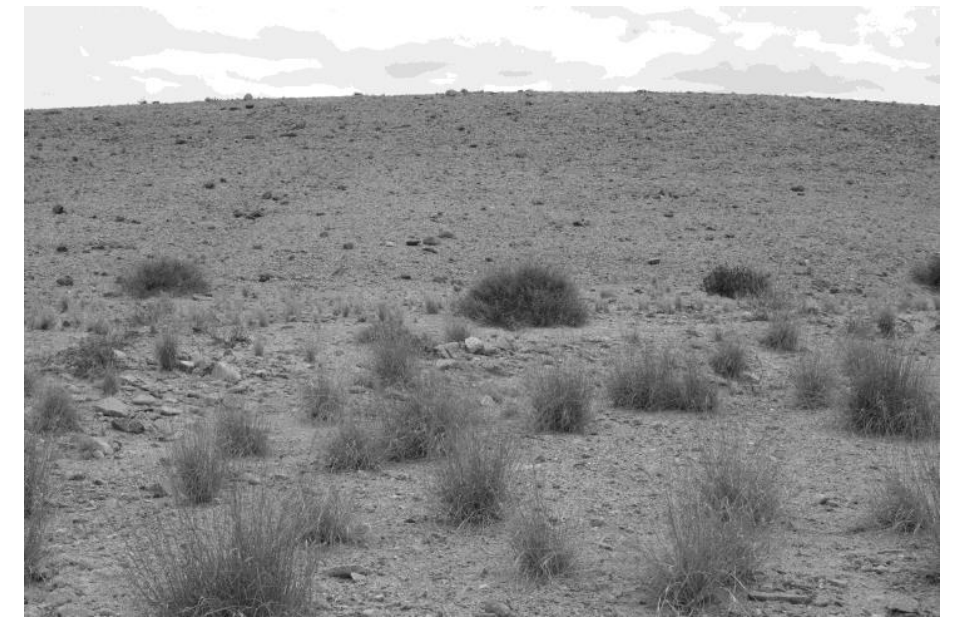

Figure 4 A natural hill slope in Namibia, subject to a typical stress and disturbance regime which has no alluvial fan at the foot. This landform would be worthy of emulation in rehabilitation of mines in this region in terms of slope and protective stone cover

Monitoring the reference sites at the same time as the rehabilitation sites may also enables the question of system resilience to be examined in real time, by looking at both the immediate effect of disturbances and tracking the recovery response.

\subsection{The monitoring toolbox}

During the period of rehabilitation, a range of monitoring tools will be needed over time, and the author commends the notion of having access to a "toolbox" of procedures, each of which will have a particular application and be phased in at appropriate times. However, all of these tools should have the capacity to 
measure progress towards the objectives articulated in Box 1. As mentioned earlier, LFA is particularly suited to looking at erosion/deposition processes, and in assessing the goods and services provided increasingly by a developing plant community. Naturally, if specific plant species or specific canopy cover values are required, then there are well-developed tools to measure these. All of the monitoring tools should have the capacity to promptly inform managers when something is going wrong and also be able to specify what to do about it. If the latter informing capacity is poor, then alternative indicators or more detailed information is needed.

\subsection{When to start monitoring}

Some workers suggest that monitoring need not start for two or three years (Nichols, 2006; Nichols and Latham, 2007; DITR, 2005). However, in the scheme the author is proposing, Box 5 indicates that monitoring should begin as soon as possible after rehabilitation operations have concluded, in order to establish a baseline from which development can be assessed. Naturally, at very early stages, it is the physical or engineered landscape that is exposed to the effects of weather, so that the initial system should focus on soil and landform stability. If the landforms and materials have been adequately designed and used, there should be little erosion, and a high retention and slow release of rainwater. These landscape properties would enable a rapid biological response. On the other hand, if either dispersive materials or inadequate landforms have been deployed, exposure to two or three years of weathering without any monitoring could well miss a major erosion event. Tongway et al. (1997) proposed that a distinction could be made between the physical/engineering contribution to rehabilitation and the biological contribution (Figure 5). The capacity to be able to do so is especially important at early stages when the new landscape is more vulnerable to disturbance. Figure 5 depicts an example of a slow decline in the engineered landscape over time, thus permitting the biota to develop rapidly; the whole landscape rehabilitation being the sum of these two components and depicted by the solid line. However, if there were partial failure of the engineered landscape, perhaps by severe erosion, then the biological response would likely be less favorable. These are circumstances that are important to monitor in the early years of rehabilitation. If monitoring were delayed in commencement crucial early trends might be missed. Also, favorable information indicating low net erosion would not be forthcoming to reassure managers. Establishing an early positive feedback loop from monitoring to management, with the intention of continuance is important.

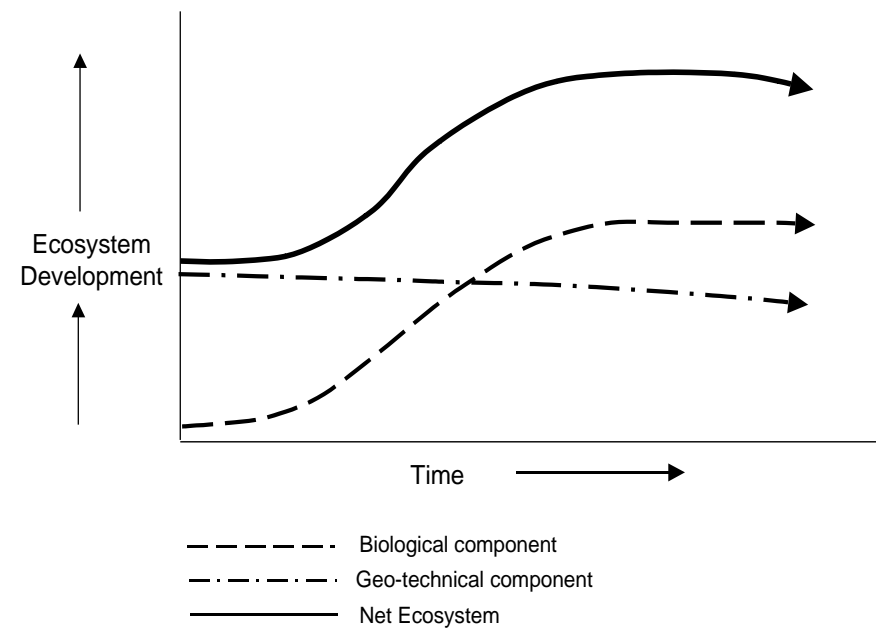

Figure 5 Depiction of physical and biological components and whole system development of ecosystem function over time

\subsection{Making prompt use of monitoring information: the adaptive learning loop}

In the general field of land reclamation, failure is rarely fully analyzed or published: mine sites are not alone here. This means that past failures are bound to be repeated unless a serious effort is made to understand the processes which failed to contribute or develop. Typically, when outcomes are not what had been hoped, there is a vague "blame-game", but little analysis. The process of deploying appropriate monitoring procedures and analyzing the emerging information stream need to be an essential input to management and 
fostering progress towards ultimate closure. To this end, an examination of the trend in ecosystem development as captured by periodic monitoring needs to be an active process which is reported accurately and speedily and with a management plan to respond to the incoming information. In particular as depicted in the adaptive leaning loop in Figure 1, this will also involve periodic re-examination of the objectives as set out in Box 1 by an adaptive learning process. There might have been a shift in final land use requirements, or too ambitious a target has been set. In this phase, some short-falls in ecosystem development need to be dealt with expeditiously by identification and analysis of the causal factors and correcting them. Data analysis may reveal a simple weather-based explanation factor such as drought slowing progress, or something more urgent such as gully formation that needs to be dealt with immediately. Partial failure may be due to selection of a non-optimum technical procedure, or a poorly implemented but otherwise sound technology. It is crucial that partial failure be analyzed critically and dealt with and thus management support also needs to be available in a timely fashion.

Reporting to regulatory agencies of the substance of periodic assessment needs to be able to articulate progress towards the agreed goals in easily understood terms, and the proposed system facilitates this. This reporting would form the basis of the eventual case for mine closure: a continuous record of performance and appropriate response to issues along the way.

\section{Conclusion}

Mine closure needs to be a well-resourced continuous process, commencing from the earliest possible stage. There are some excellent industry examples to replicate. The process requires a logical sequence of:

- Setting objectives with social and ecological dimensions.

- Identifying the ecological imperatives.

- Selecting and implementing the most appropriate technology.

- Immediately commencing monitoring the ecological response.

- Actively and promptly reviewing monitoring information.

By stepping through this sequence, the inadequacy of simply copying techniques from elsewhere, regardless of suitability will be avoided. This process will result in a growing body of objective information, logically organized, and defendable in terms of ecological functioning, and ultimately providing more compelling cases to present to regulatory bodies for closure.

\section{References}

Cobby, G. (2007) Western Australian Regulatory Approach to Mining Approvals and Mine Closure. Mine Closure 2007, A.B. Fourie, M. Tibbett and J. Wiertz (eds), pp. 103-106.

DITR (2006) Overview, Leading Practice Development Program for the Mining Industry. Department of Industry, Tourism and Resources, Canberra, Australia.

Grant, C.D. (2006) Decommissioning Alcoa's first bauxite mine in the Jarrah forest of Western Australia-Cradle to grave. In Mine Closure 2006, A.B. Fourie and M. Tibbett (eds), pp. 287-298.

Grant, C.D. (2007) Developing completion criteria for Alcoa's Bauxite mine rehabilitation in Western Australia. In Mine Closure 2007, A.B. Fourie, M. Tibbett and J. Wiertz (eds), pp. 156-164.

Nichols, O.G. (2006) Developing Completion Criteria for Native Ecosystem Reconstruction-A Challenge for the Mining Industry. Mine Closure 2006. A.B. Fourie, M. Tibbett (eds), pp. 61-75.

Nichols, O.G. and Latham, C. (2007) Assessing rehabilitation success in semi-arid, unpredictable environments implications for completion criteria. In Mine Closure 2007, A.B. Fourie, M. Tibbett and J. Wiertz (eds), pp. 789-802.

Spain, A.V., Hinz, D.A., Ludwig, J.A., Tibbett, M. and Tongway, D.J. (2006) Mine Closure and Ecosystem Development-Alcan Gove Bauxite Mine, Northern Territory, Australia. Mine Closure 2006, A.B. Fourie and M. Tibbett (eds), pp. 299-308.

Sutton, M.W. and Weiersbye, I.M. (2007) South African Legislation in Gold Mine Closure and Residual Risk. In Mine Closure 2007, A.B. Fourie, M. Tibbett and J. Wiertz (eds), pp. 89-102.

Tongway, D. and Hindley, N. (2004) Landscape Function Analysis www.cse.csiro.au/research/efa/index.htm, 84 p.

Tongway, D., Hindley, N., Ludwig, J., Kearns, A. and Barnett, G. (1997) Early indicators of ecosystem rehabilitation on selected minesites. $2^{\text {nd }}$ Annual Environmental Workshop. Minerals Council of Australia, Dickson, Australia. 